\title{
EXPERIMENTS WITH ANIMALS ON THE COMBINED ACTION OF PROCAINE AND BARBITURATES
}

\author{
Madelaine O Maykut, M.A., " and Werner Kalow, m.D. $\dagger$
}

\section{INTRODUCTION}

Two principal effects of procaine on the central nervous system are known: excitant effects as manifested by convulsions, and depressant actions. Of the depressant actions, respiratory paralysis was the most obvious (1). A central analgesic action was then described $(2,3)$. More recently a hypnotic or anaesthetic effect in humans was observed. It was found that injections of procaine during anaesthesia would reduce the need for anaesthetic agents like thiopental, cyclopropane, or nitrous oxide $(4,5)$. Allen, Crossman and Lyons $(6)$ and Wright (7) have used procaine as the main general anaesthetic agent with some premedication with barbiturate.

The clinical studies suggested synergism between procaine and barbiturates with respect to anaesthetio or hypnotic action. On the other hand, it is well known that barbiturates counteract the convulsions due to procaine, that is, in this respect the drugs are antagonists $(8,9)$. It was of interest to us to survey a system where both antagonistic and synergistic trends are present.

\section{Materials AND Methods}

All figures on doses and concentrations in this paper $r \in f e r$ to the salts procaine hydrochloride, sodium pentobarbital (Nembutal), and sodium thiopental (Pentothal).

The experimental animals were white guinea-pigs of both sexes, with an average weight of $574 \pm 13 \mathrm{gm}$ Some rabbits weighing between 2 and $4 \mathrm{~kg}$. were used in addition.

Four series of experiments were performed on guinea-pigs. Common to these experiments was the following routine. The hair was clipped over the areas where injections were to be made. Sodium pentobarbital in 0.5 per cent solution was injected intramuscularly into both thighs of the animal. Immediately afterwards, procaine in a 2 per cent solution was injected subcutarieously on both sides of the back. When only one drug was given, physiological salıne was injected instead of the other drug.

The first serres of experiments was designed to survey broadly the effects of the combination of procaine and pentobarbital. Three guinea-pigs were tested at each dose level. Each animal was closely observed and notes were taken. The most conspicuous and consistent symptoms were subsequently translated to symbols explained in Fig. 1.

\footnotetext{
${ }^{\circ}$ Research Fellow of Shouldice Surgery, Toronto, Canada

fFrom the Department of Pharmacology, Unversity of Toronto
} 


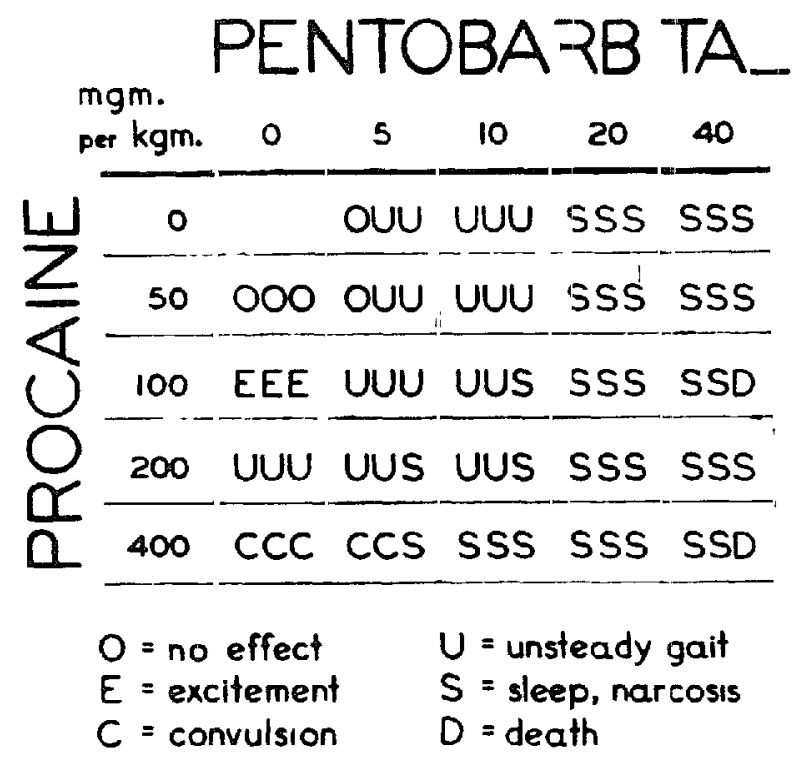

Fig. 1. Symptoms of individual guinea-pigs given vanous dose combinations of pentobarbital (Nembutal) and procaune

In the next experimental series, "sleeping times" were measured. These were defined as the times of absence of the righting reflex. Seven determinations were made at each dose level.

The acute toxicities of pentobarbital and procame, alone and in combination, were determined in the thurd series of experiments. All deaths occurred within six hours after the injections. The LD50's and their standard errors were estimated as described by Finney (10).

In experiments dealing with re-1nduction of sleep, procaine was injected not immediately after pentobarbital but at the first attempt of the guinea-pigs to move about while the effect of the barbiturate was ceasing.

The re-induction of sleep was also tested in rabbits using thiopental and procaine, both in 1 per cent solution, and both injected intravenously. An ear vein was cannulated with fine plastic tubing so that mjections could be made without restraining the animal. Thiopental was injected to induce sleep for ten to fifteen minutes The tube was then flushed with saline. The injection of procaine was started very slowly as soon as the righting reflex reappeared and was continued at a slightly increased rate until the rabbit was on its side again.

\section{RESULTS}

The most prominent symptoms of individual animals after injection of pentobarbital and procaine are shown in $F_{2}$. 1 . Convulsions due to the highest dose of procaine alone are indicated in the lower eft-hand corner of the diagram Even small doses of pentobarbital suppresse 1 this incidence of convulsions. Sodium pentobarbital, $10 \mathrm{mg}$. $/ \mathrm{kg}$., used alone did not produce sleep but by the addition of higher doses of procaine sleep was induced. The last column of the diagram records two deaths when procaine and pentobarbital were combined The results of this survey allowed the selection of suitable dose combinations for further studies. 
At first the hypnotic action of the combined drugs was investigated. It was found that for comparison of different dose levels the duration of sleep-was easier to measure than the depth of sleep. The doses used for sodium pentobarbital were $15,21.3$, and $30 \mathrm{mg} . / \mathrm{kg}$. and for procaine 100,200 , and $400 \mathrm{mg} . / \mathrm{kg}$. Seven guinea-pigs were used or each dose combination. All animals slept and none died. The results of these experiments are presented in the three-dimensional diagram (Fig 2). The increasing doses of procaine are plotted on one axis from

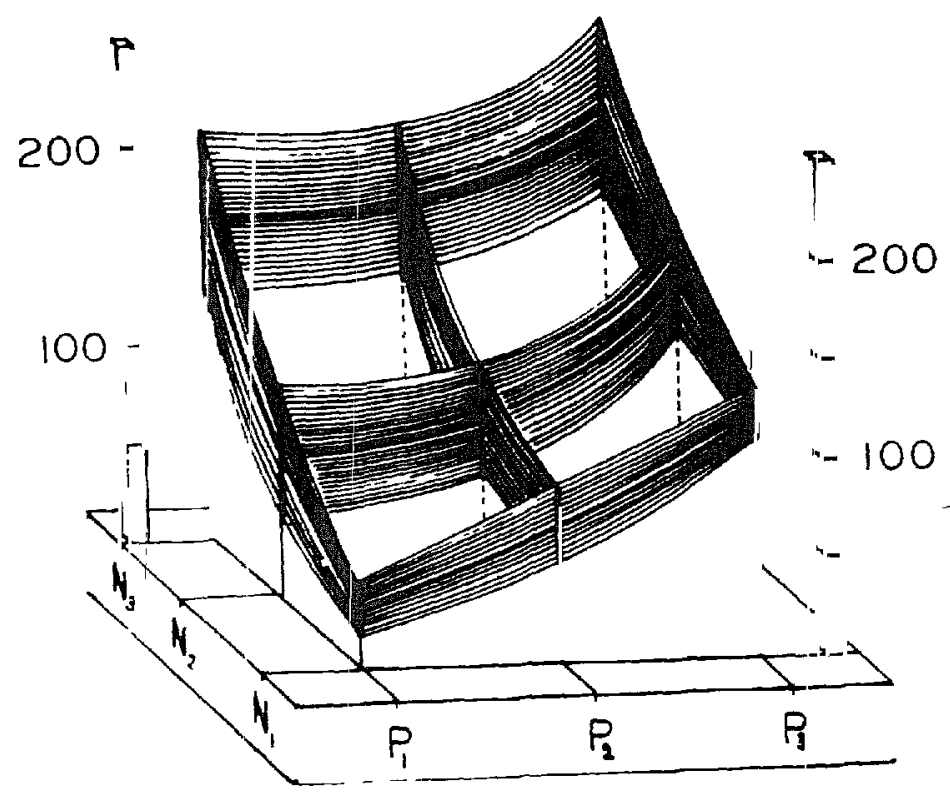

Fig 2 Hypnotic action of combinations of procaine and pentobarbital (Nembutal) in gunea-pigs.

The two horizontal axes represent uncreasing doses of the two drugs, $P$ stands for procaine, $\mathrm{N}$ for pentobarbital. The vertical axis represents sleeping time in minutes The fence-luke structure denotes the standard error of the mean sleeping time.

P1 to P3 and those of pentobarbital along the other axis from N1 to N3. The duration of sleep in minutes is represented by the height of the figure indicated by the two yardsticks. The average sleeping time is shown by the heavy lines joinıng the different dose combinations. The fence-lıke structure enclosing these lines represents the standard error of the mean. The lowest dose combination of pentobarbital and procaine (N1PI) gave rise to the sleeping time of about 30 minutes; the highest dose combination (N3P3) to 210 minutes. The surface of the diagram is curved. The fence-like structure is low for the low dose of pentobarbital and increases with increasing doses of pentobarbital. Although procaine also increases the sleeping time, the standard error does not increase with the dose of procaine.

The data were subjected to statistical analysis. Both procaine and pentobarbital have a signilicant influence on the sleeping time. There is also a significant increase of the error with increasing dose of pentobarbital, while the error does not change with increasing doses of procaine (11).

Another set of experiments was made to determine whether sleep could be 
re-induced in guinea-pigs by the injection of procaine after the effects of pentobarbital had ceased. The sleep after the intramuscular injection of $30 \mathrm{mg} . / \mathrm{kg}$. of sodium pentobarbital lasted approximately one and a half hours. A dose of 200 $\mathrm{mg}$. $/ \mathrm{kg}$. procaine re-induced sleep in 3 out of 5 animals; $300 \mathrm{mg} . / \mathrm{kg}$. in 5 out of 5 animals. The re-induced sleep lasted approxumately 100 minutes in the latter group. The sleep after the procaine injection was not so deep as that after pentojarbital mjection. The bodies of the guinea-pigs appeared relaxed upon lifting, them. However, an incomplete degree of relaxation was evident from occasiona. movements such as rolling over during the sleep. In experiments using rabbits, 5 out of 5 animals were forced back on to their sides with procaine injected intravenously during recovery from narcosis due to thiopental. The amounts of thropental were $15-20 \mathrm{mg} . / \mathrm{kg}$., of procame $12-16 \mathrm{mg} . / \mathrm{kg}$. Muscular relaxation could not be achieved.

Data on the acute toxicities in guinea-pigs of procaine and pentobarbital alone and in combination are presented in Table I. The influence of procaine on the

\section{TABLE I}

Acute Toxicities of Pentobarbital and Procaine, Alove and in Combination

Pentobarbital, intramuscular. Procaine, subcutaneous

\begin{tabular}{lccc}
\hline & $\begin{array}{c}\text { LD50 } \pm \mathrm{S} \mathrm{E} \\
\mathrm{mg} / \mathrm{kg}\end{array}$ & Slope & $\begin{array}{c}\text { Number of } \\
\text { gunea-pigs }\end{array}$ \\
\hline $\begin{array}{l}\text { Pentobarbital Sodium } \\
\begin{array}{l}\text { Pentobarbital Sodium } \\
+300 \mathrm{gm} / \mathrm{kg} \text { Procaine }\end{array}\end{array}$ & $425 \pm 47$ & 79 & 35 \\
$\begin{array}{l}\text { Procaine } \\
\begin{array}{l}\text { Procaine } \\
+10 \mathrm{mg} / \mathrm{kg} \text { Pentobarbital } \\
\text { Sodium }\end{array}\end{array}$ & $438 \pm 23$ & 54 & 35 \\
\hline
\end{tabular}

*Probit units per log dose

LD50 of pentobarbital, as well as of pentobarbital on the LD50 of procaine, is significant. If $70.3 \mathrm{mg} . / \mathrm{kg}$. is the LD50 of pentobarbital, $42.5 \mathrm{mg} / \mathrm{kg}$ corresponds to the LD4, while the lethal effect of $10 \mathrm{mg} . / \mathrm{kg}$. is negligible ( $<\mathrm{LD1} 0^{-6}$ ). If $438 \mathrm{mg}$. $/ \mathrm{kg}$. is the LD50 of procaine, $674 \mathrm{mg}$. $/ \mathrm{kg}$. corresponds to the LD97, while $300 \mathrm{mg} . / \mathrm{kg}$. represents the LD4.

\section{Discussion}

Our investigations on the duration of sleep have shown that procane, capable of producing convulsions, is also capable of increasing the central depression due to pentobarbital. This could have one of two meanings: procaine either mhbits the elimination of pentobarbital or has a central depressing action. The expernments on the re-induction of sleep and the toxicity studies seem to favour the latter assumption. That is, the central depression due to procaine becomes 
particularly evident if the convulsive component is suppressed by the addition of barbiturates. This conclusion supports previous observations by a number of different authors who claimed a central analgesic and depressant effect of procaine $(2,3,4,6,7,12,13)$. The doses of procaine as well as of pentobarbital which were found effective in this study appear to be comparable to those used clinically if body surface is made the basis of comparison.

The relation between toxic and hypnotic effects of the two drugs is summarized in Fig. 3. The dose of pentobarbital is presented on one axis, the dose of procaine on the other. The lines in the diagram indicate equally effective dose combinations. The upper curve represents our data on the LD50's, the three lower curves are derived from observed and interpolated data which were presented in the three-dimensional diagram of Fig. 2. In such a plot as Fig. 3, a strictly additive effect is characterized by a straight line connecting both axes.

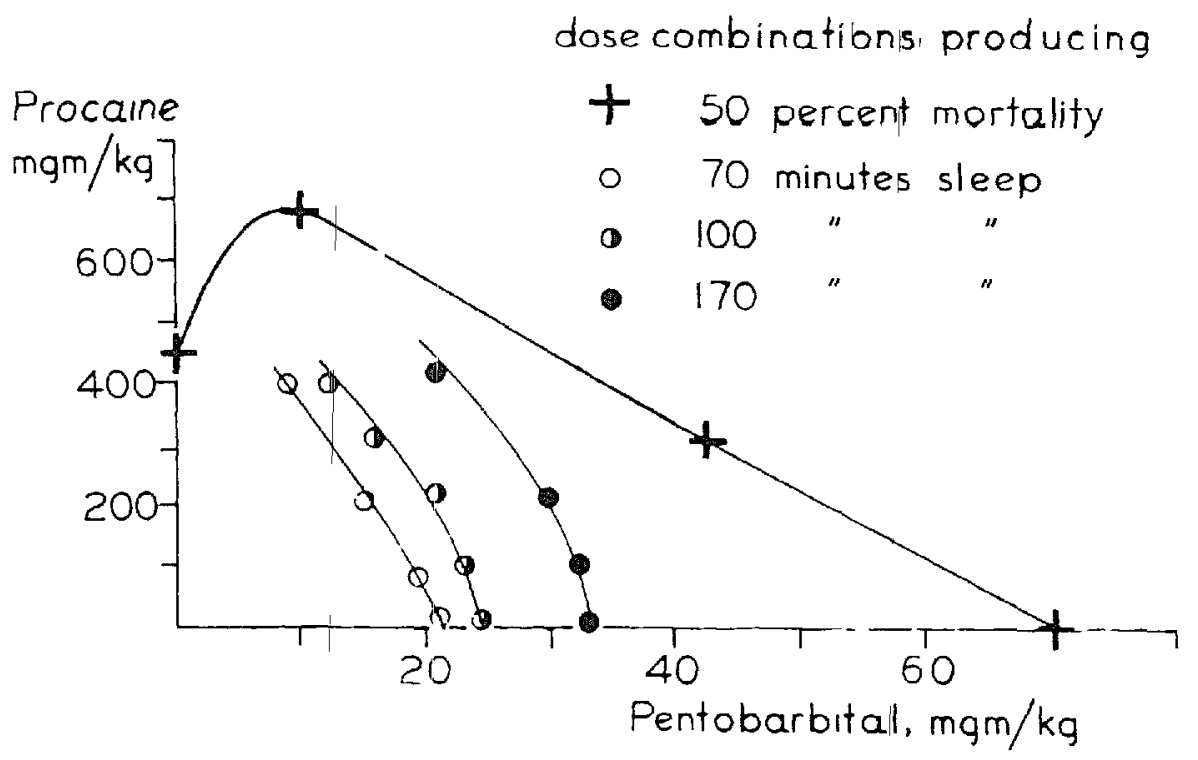

Fig. 3. Summary of data on the combined effects of pentobarbital (Nembutal) and procaine. Upper curve: LD50's of pentobarbital and procaine, alone and in combination.

Lower curve: Dose combinations producing the same hypnotic action (cf. Gaddum (1940) Fig. 65, i.e. Fig. 76 in 4 th ed., 1953).

The hump of the upper curve indicates the well-known antagonism of pentobarbital to the toxicity of procaine. Considering the experimental point at 42 $\mathrm{mg} / \mathrm{kg}$. of pentobarbital, by combining an LD4 of procaine and an LD4 of pentobarbital, we obtained 50 per cent mortality. The LD4 of pentobarbital is 42 $\mathrm{mg}$. $/ \mathrm{kg}$. Twice the LD4 of pentobarbital ( $84 \mathrm{mg}$. $/ \mathrm{kg}$.) should kill 74 per cent, as indicated by the probit analysis. Thus, if procaine and pentobarbital could replace each other for their lethal actions, our drug combination should have killed 74 per cent instead of the observed 50 per cent. That is, the effect of $300 \mathrm{mg} . / \mathrm{kg}$. procaine is slightly less than additive to that of $40 \mathrm{mg} . / \mathrm{kg}$. pentobarbital. Loewe (14) classifies such an effort as a type of antagonism, Gaddum (15) as a type of synergism. Loewe's designation would give the intellectual satisfaction that the two drugs are called antagonists under all circumstances. The disadvantage of 
this classification, however, is obvious. A patient under toxic influence of procaine may be saved by an administration of pentobarbital; a case of barbiturate poisoning could become fatal with an additional injection of procaine.

We interpret the combined action as follows. Procaine has at least two independent lethal actions on the central nervous system. One is counteracted by pentobarbital. The other appears to be augmentative to and perhaps identical in mechanism with the lethal action of pentobarbital. A similar mode of depressant action is suggested by the linearity of the major portion of the mortality curve of Fig. 3.

An extrapolation of the three lower curves (Fig. 3) towarcs the ordinate would give us theoretical values for the hypnotic activity of procane. This action of procaine is probably not completely additive to that of pentobarbital The extrapolated portions of the three curves would intersect the mortality curve. This means, first, that the hypnotic effect of procaine cannot be ordinarily demonstrated because of the existence of the convulsive action; secondly, it again suggests independence of the two effects of procaine.

The course of the mortality curve and the sleeping curves shows that the margin of safety (that is, the ratio of the toxic dose to the effective dose) is diminished if we enhance the narcotic action of pentobarbital by procaine. For a range of doses this disadvantage may perhaps be outweighed by the greater predictability of the actions of procaine. Table I indicates the steep mortality curves of procaine. As shown in Fig. 2, the standard error of the sleeping tme increased with increasing doses of pentobarbital but remained constant with increasing doses of procaine. It means that if we want to produce sleep of a given duration, we have a better chance to hit the right time by combining pentoJarbital with procaine in proper doses, than by using pentobarbital alone.

\section{SUMMART}

Procaine prolonged the sleep of guinea-pigs induced by pentobarbital.

Procaine could re-induce sleep in guinea-pigs and rabbits after the apparent effects of pentobarbital or thiopental respectively had ceased. This is evidence of an hypnotic effect of procaine rather than of an influence on the elimination of the barbiturate. The hypnotic and the convulsive effects seem to represent two independent actions of procaine.

The effect of procaine on the toxicity of pentobarbital was nearly additive. The effect of pentobarbital on the toxicity of procaine was antagonistic.

The distribution of standard errors of the sleeping times allowed the conclusion that the duration of the sleep could be better predicted if induced by the conbination of pentobarbital and procaine than by pentobarbital alone. However, we appeared to lose on the margin of safety with this combination of drugs.

\section{ACKNOWLEDGEMENTS}

Thanks are due to Dr. E. E. Shouldice who initiated and partly financed this investigation; Professor G. H. W. Lucas for his interest; and Professor J. K. W. Ferguson for his stimulating criticism. We are indebted to Dr. B. A. Griffith of the Department of Mathematics and to Dr, D. B. W. Reid of the Department of 
Epidemiology and Biometrics for their efforts to analyse an unusual statistical problem.

\section{RÉSUMÉ}

Le synergisme autant que l'antagonısme ont été signalés dans les écrits sur l'action combinée de la procaine et des barbituriques. En conséquence, on a entrepris une étude expérimentale sur l'influence réciproque des deux drogues. La procane prolonge chez les cobayes l'anesthésie initiée par le pentobarbital. La procaine a pu provoquer à nouveau le sommeil chez les cobayes et les lapins après que les effets apparents du pentobarbital ou du thiopental eussent respectivement cessé. Cela met en évidence un effet hypnotique de la procaine plutôt qu'une influence sur l'élimination des barbituriques. La toxicité aigue des deux drogues, seules ou en combinaison, a été mesurée en déterminant la dose mortelle (LD50) chez les cobayes. L'effet du pentobarbital (acide diethyl-pentobarbiturique) sur la toxicité de la procaine a été antagonıste L'effet de la procaine sur la toxicité du penobarbital, cependant, a été presque additif.

Les effets hypnotiques et les effets convulsifs paraissent représenter deux actions indépendantes de la procaine. La distribution des erreurs normales permet de prévoir la durée du sommeil relativement mieux avec la combinaison qu'avec le pentobarbital seul. Cependant, cet avantage semble être contrebalancé, puisqu'on perd sur la marge de sécurité avec cette combinaison de drogues.

\section{REFERENCES}

1 Hrlu, E F \& Macdonald, A D The Action of Local Anesthetics on the Respiratory Apparatus J Pharm \& Exp Therap 53 454 (1935)

2 Bigelow, N \& Hanfison, I General Analgesic Effects of Procane J Pharm \& Exp. Therap 81368 (1944)

3 Hewer, A J H \& Keele, C A A Method of Testng Analgesics in Man Lancet 255 683 (1948)

4 Edmonds, G W, Comor, W H, Kennedy, J D \& Taylor, I B Iritravenous Use of Procame in General Anesthesia J A M A 141761 (1949)

5 Biтtruch, N M Discussion on Intravenous Use of Procane J A M A 141766 (1949).

6 Allen, F M, Crossman, L W \& Lyans, L V Intravenous Procaine Analgesia Current Researches in Anesth \& Analg 25 1 (1946).

7 Wright, G V S Intravenous Procaine Hydrochlonde. Anesthesia 5. 201 (1950).

8 Knoefel, P K, Herwick, R P \& Loevenhart, A. S The Prevention of Acute Intoxicaton from Local Anesthetics J Pharm \& Exp Therap 39397 (1930).

9. Migliarese, J F, Bauer, E. C \& Randall, L O Prevention of Procame Convulsions by Presidon and Sodium Pentobarbital Proc Soc. Exper Biol \& Med 7353 (1950)

10 Finney, D J In Burn, J H Biological Standardization 2nd ed, London Oxford University Press (1950)

11 Snedecor, G W Statistical Methods 4th ed, Ames, Iowa Iowa State College Press (1950) (Bartlett's test, p 251)

12 Brittain, G J C Intravenous Procaine Hydrochlonde Anesthesia 430 (1949).

13 Graubard, D. J \& Peterson, M C. Climcal Uses of Intravenous Procaine Oxford Blackwell (1951) Britsh Commonwealth edızon, ed by W. W. Mushn.

14 Loswe, S Die quantitativen Probleme der Pharmakologie. Erg. Physiol 2747 (1928).

-- The Problem of Synergısm and Antagonism of Combined Drugs. Arzneumittel Forsch. 6285 (1953).

15 Gaboum, J H Pharmacology lst ed, London Oxford Unversity Press (1940). 4th ed., 1953 